\title{
A Teacher's Perspective of Interacting with Long-Term Absent Students through Digital Communications Technologies
}

\author{
Anthony Jones and Karina Wilkie \\ Graduate School of Education, University of Melbourne, Australia \\ a.jones@unimelb.edu.au
}

\begin{abstract}
This paper uses an hypothetical scenario to report on the use of ICT to enable students with a chronic illness to partly overcome prolonged absence for school. The focus is on the responses of teachers when one of their students can no longer attend school regularly as a consequence of a serious illness, but wants to continue their education. The special education needs of students participating in the Link ' $n$ Learn project result from a desire to continue studying while absent from school for prolonged periods. It appears that this desire for continuity is misunderstood by many adults, including teachers. Discussion is centred around a hypothetical case study of two teachers as they work with students absent for an extended period.
\end{abstract}

Keywords: Online learning, Students absent from school.

\section{Introduction}

To set the scene for the discussion, a brief scenario is presented and then there are some comments on teachers deciding what content to teach and how best to teach it.

\section{Hypothetical Scenario}

Parkside Secondary College is a rural/outer suburban school of some 900 students and 75 teachers. In this scenario these details, including whether Parkside is part of a government, independent or Catholic system, are not relevant. What is described here is meant to be general because Parkside could be a secondary school in any developed country.

Sam has been teaching at Parkside for three years, and overall has ten years teaching experience. Like many teachers Sam has a notebook computer that is used both at school and at home for preparation, marking, and administration.

Several weeks into Term 2 one of Sam's students is diagnosed with a chronic illness and will be absent from class for several months. A few weeks later Sam is contacted by the student's parents with a request to help the student continue studying. Sam wonders "How?", "What?", "Why?" 


\section{Reality}

Interviews with teachers indicate that it is not uncommon for classroom practitioners to first consider pragmatic issues such as "How?" and "What?" when faced with a situation like Sam's. It is the latter of these two questions that causes most problems for teachers. It also appears that it is only later that they ask themselves why a student with a life threatening health condition wants to continue with their schooling.

Link ' $n$ Learn is a research project based at the Royal Children's Hospital ( $\mathrm{RCH})$, a large hospital for young people 16 years of age or less. The RCH is located in Melbourne, Australia, and while the data that informs this paper comes from this hospital, children's hospitals in the UK and Europe are collecting similar data.

Hospitals such as the $\mathrm{RCH}$ are treating increasing numbers of primary and secondary students for illnesses that are long-term, life threatening and result in prolonged absences from school. For example in 2007 the RCH Education Institute supported 1528 students, 1146 of whom spent less than 3 weeks in hospital [1]. On the other hand there are students who have been supported for several years, as they have been unable to attend school because of ongoing cycles of treatment and recuperation. One consequence is that it is becoming more likely that a school will face Sam's dilemma as sketched above. Some responses and suggestions are offered below, structured around the three questions Sam asked, and with evidence from the Link ' $n$ Learn research project. Previous discussions of findings from Link ' $n$ Learn have concentrated on students and their perspectives and experiences in maintaining some degree of continuity in their education [1], [2].

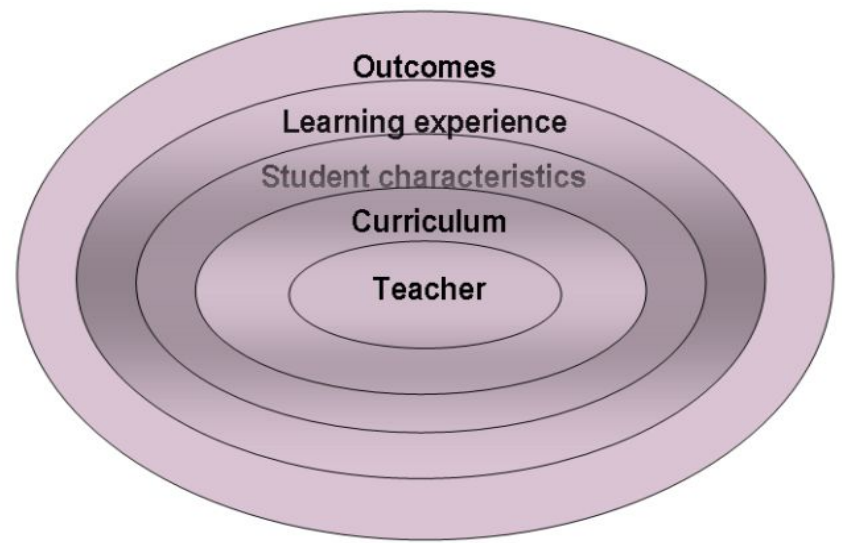

Fig. 1. Classroom teaching model

The issue of how to help these students appears to be the most readily answered of the three questions. Together with a number of other projects, Link ' $n$ Learn has clearly demonstrated that ICT running on small computers with internet access is capable of providing adequate connections between teacher and student, either on a one-to-one basis or with the absent student digitally participating in a lesson. Digital technology has reached the stage where even inexperienced users of web-based video 
communications software, a group that includes many teachers, are able to quickly and easily learn to use the technology.

Figure 1 represents one model of how a classroom might work from a teacher's perspective. The teacher is at the centre because classroom teachers are not nonparticipating observers of what occurs in their classroom. Teachers have a curriculum that the system, the school, colleagues, parents and students expect will inform all of them about the content to be taught and learned. Classroom teachers usually collaborate with colleagues to make specific decisions about content. From a student's viewpoint the curriculum is defined by the tasks, experiences and activities used by the teacher. In this model, unless it is part of the content, ICT is usually one aspect of a multitude of learning experiences

\subsection{Theory}

Although this model suggests that there are distinct layers or steps, in reality many of these layers overlap. Often teachers simultaneously consider some content, the characteristics of the students in the class, and what are likely to be successful teaching strategies. This was labelled as teacher pedagogical content knowledge by Shulman [3] and is represented in Figure 2.

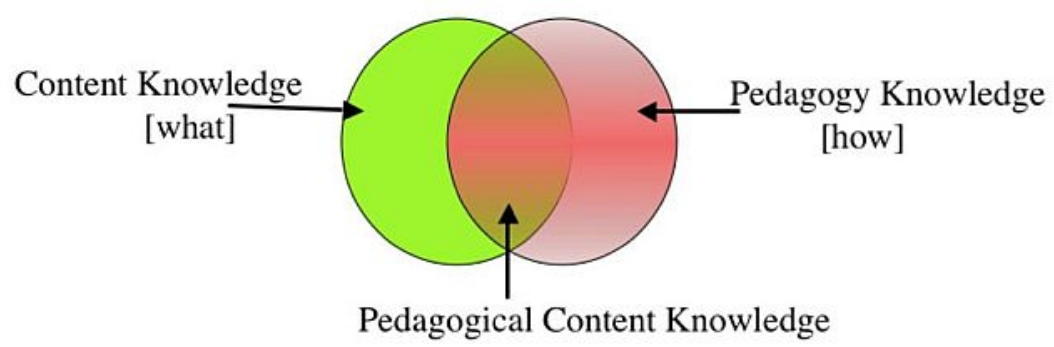

Fig. 2. Pedagogical content knowledge. (After Shulman [3]).

Teachers use their pedagogical content knowledge (PCK) to decide which learning experiences they plan to have students engage with. Teachers might have a choice that includes concrete materials (blocks, science equipment), puzzles, games, worksheets, role plays, textbook, or technology (computer hardware and software). There are many ways of presenting content, so to there are many very different learning experiences that can be provided for students.

The concept of PCK was introduced in the very early days of school and classroom use of computers. Undoubtedly this is one of the reasons why technology is not specifically mentioned. Assuming that technology is connected to content and pedagogy, it must be asked where and why technology fits into PCK. Two possible positions on this are first that technology for teaching and learning is just of the many components of PCK and shouldn't be given more prominence than other components, and second that the use of technology for teaching and learning is so important that it has to be included in a modified definition of PCK. This second position was taken by Mishra and Koehler [4] in their proposal of technological pedagogical content knowledge 
(TPCK), and further modified in Thompson and Mishra's [5] technological, and content, pedagogical knowledge (TPACK). For many educators these two proposals do not reflect exemplary classroom practice because technology is named first and this implies a hierarchy. It can be argued that TPCK and TAPCK are a reversion back to the concept of technocentrism raised by Papert and others in the 1980s [6]. Papert attempted to change the idea of learners as passive receivers of knowledge by giving them "control over their learning with computers. Children were the agents of thinking and learning - not the computer ... Computers cannot produce "good" learning, but children can do "good" learning with computers" [7 p.41]

\section{The Reality of the Classroom}

The Link ' $n$ Learn project has been operating for more than two years and over 30 students with a chronic illness have participated. While the majority of students have been in the compulsory years of schooling age range, a significant number of older students who are attempting to complete their secondary education and go on to tertiary study have been involved. Reactions of teachers who are confronted with the situation suggested in the hypothetical scenario range fro denial to a desire to assist as much as possible.

Unfortunately denial, or at least a high degree of unwillingness to help students who are going to be absent from school for an extended period, is not uncommon. Among those in Link ' $n$ Learn who have not received appropriate support from teachers or schools have been students waiting on a transplant (heart, kidney, bone marrow), students with cancer and a variety of other chronic illnesses. These cases will not be considered further here as the focus is on those teachers who have accepted the challenge of using digital technologies to continue the education of an absent student.

Teaching in a classroom with the assistance of IT is relatively straightforward for most teachers. Using a single computer in a classroom usually means that the teacher is demonstrating something, for example an internet web-site or a multimedia simulation, or that a presentation is being made using a web browser or presentation software. Teaching in a computer room is more difficult for teachers to manage, control and monitor. However it is still relatively simple.

However what happens when one student from a class of 25 is not physically present in the classroom for weeks or months? In this situation the degree of control that teachers normally have over student learning is reduced significantly, partly because the student now determines when they will participate, based on how well they are and current treatment. Technically it is not difficult to set-up and implement a stable electronic video and audio communications link from one computer to another - in this case between a teachers to a student.

\subsection{Discussion}

In this section two short excerpts from the Link ' $n$ Learn project are presented. Although pseudonyms are used to protect the privacy of students and teachers, the context and description are authentic. 
Ernest was in Year 9 at a government secondary school some 200 kilometres north of the RCH, and Ms F was his English teacher. In February of the year Ernest was hospitalised with acute renal problems, Ms F offered to try connecting Ernest to English lessons with his class twice weekly. This choice of lessons was determined by times that Ernest was free from dialysis or other treatment. Although Ms F had used Skype previously for social purposes, she had neither experience nor training in teaching in this mode. In spite of these potential impediments Ernest connected to his English classes through his and Ms F's computers. The class did not see Ernest, but knew he was participating in the lesson through Skype. When the lesson finished Ernest and Ms F had a couple of minutes to discuss what should be done before the next lesson.

Mr T taught Grade 5 at a school located approximately 100 kilometres from the $\mathrm{RCH}$. Jo, one of his students, was an articulate and technologically savvy student being treated for a cancer. Because of cycles of chemotherapy at the $\mathrm{RCH}$ followed by recuperation at home, Jo was absent from school more often than she was present. However Jo knew what was happening at school, both educationally and socially, through social networking. In an interview early in her treatment cycle Jo revealed that she connected to school friends through four different social networking sites. A few selected friends were members on all four sites, but each site was used for different purposes. One site appeared to include all the girls from Jo's class and most of the boys, while another was restricted to girls who were members of a local sporting organisation. Through these social networking sites Jo kept abreast of what happened at school and in her local community. Jo was not particularly interested in communicating with Mr T while she was in hospital, but she did connect with him electronically while recovering at home.

Jo's knowledge of what happened in class surprised Mr T, and initially he was uncertain about how and which school work could be covered online. It quickly became apparent that responding to Jo's questions about specific topics or problems was an appropriate strategy. If she didn't understand something that her friends told her, she would ask Mr T.

Eventually, after more than six months absence, Jo returned to school as a full time student and the video conferencing sessions with $\mathrm{Mr} \mathrm{T}$ stopped. In this case teacher and student were able to overcome the problem of what to do in a one hour online video conferencing session that was replacing several days of school attendance, by allowing the student to take the initiative and to ask about things she had heard from others but didn't understand.

The distance between the hospital and a students' school appears to have an impact on what teachers think is the best strategy for continuing the education of a student. In theory, digital communications such as online video conferencing between teacher and student, could be used no matter where the school was located. However there were several cases where students from schools within ten kilometres of the hospital preferred to make regular visits to the hospital to talk with the student, deliver work, and collect completed work. In at least one case this appears to be a direct result of a student being disfigured by burns to the upper body, and consequently not wanting to be seen by peers and teachers. Even though the possibility of allowing the student to use online video conferencing to see the teacher and class without being seen themself was discussed, this student preferred not to.

In reflecting on the data collected for the Link ' $n$ Learn project, the two most significant findings at this stage relate to the desire of students to continue their schooling, 
and the attitude of teachers who have successfully enabled this to occur. To the surprise of many adults, including some parents, some medical staff, and most teachers, students with a chronic illness who know they would be absent from school for an extended period wanted to continue their education. The students accepted that in some cases they might have to reduce the number of subjects being studied, but almost every student in the Link ' $n$ Learn project who was at upper primary level or above expressed a desire to work around periods of medical treatment, ill health, and recuperation to maintain a level of academic continuity.

The most problematic group in the Link ' $n$ Learn project have been school administrators and classroom teachers. For Ms F, Mr T, and other teachers in the Link ' $n$ Learn project, a desire to assist the absent student is a much more reliable indicator of success than the technological competence of the teacher [2].

\section{Conclusion}

In 2010 video conferencing and other formats of electronic communication are readily available to teachers and students in hospital. When hospitalised students are loaned a netbook computer and have internet access through a wireless network, there is no technological reason for not connecting with their teachers.

In order to obtain registration to teach in Australia, applicants must have passed IT subjects in their pre-service teacher education course. However these pre-service courses are usually too short to allow candidates to gain experience with one-to-one online teaching strategies that would be appropriate for use with hospitalised students. Currently the success of educational connections between hospitalised students and their teachers is highly dependent on the personal willingness of teachers to move into pedagogical areas for which they have neither training nor experience. As more students are diagnosed with a chronic illness it is time for system administrators to ensure that schools and teachers are prepared for this eventuality.

\section{References}

1. Potas, T., Jones, A.: Ethics, Equality and Inclusion for Students with a Chronic Health Condition. In: Kendall, M., Samways, B. (eds.) Learning to Live in the Knowledge Society, pp. 71-78. Springer, New York (2008)

2. Wilkie, K.J., Jones, A.: Link and learn: Students connecting to their schools and studies using ICT despite chronic illness. In: Jeffery, P.L. (ed.) AARE 2008 Conference Papers Collection, pp. 1-13. Australian Association for Research in Education, Melbourne (2009)

3. Shulman, L.S.: Knowledge and teaching: Foundations of the new reform. Harvard Educational Review 57(1), 1-22 (1987)

4. Mishra, P., Koehla, M.: Technological pedagogical content knowledge: A framework for teacher knowledge. Teachers College Record 108(6), 1017-1054 (2006)

5. Thompson, A.D., Mishra, P.: Breaking news: TPCK becomes TPACK! Journal of Computing in Teacher Education 24(2), 38, 64 (2007)

6. Papert, S.: Computer criticism vs. technocentric thinking. Educational Researcher 16(1), 22 30 (1987)

7. Harel, I., Papert, S. (eds.): Constructionism, 2nd edn. Ablex Publishing Corp., Norwood (1993) 